\section{(6) OPEN ACCESS}

\title{
The allure of the waterpipe: a narrative review of factors affecting the epidemic rise in waterpipe smoking among young persons globally
}

\author{
E A Akl, ${ }_{1}^{1}$ K D Ward, ${ }^{2}$ D Bteddini, ${ }^{3}$ R Khaliel, ${ }^{3}$ A C Alexander, ${ }^{2}$ T Lotfi, $^{4}$ H Alaouie, ${ }^{3}$ \\ R A Afifi ${ }^{3}$
}

${ }^{1}$ Department of Internal Medicine, American University of Beirut, Beirut, Lebanon ${ }^{2}$ School of Public Health, University of Memphis, Memphis, Tennessee, USA ${ }^{3}$ Faculty of Health Sciences, American University of Beirut, Beirut, Lebanon

${ }^{4}$ Faculty of Medicine, Clinical Research Institute, American University of Beirut, Beirut, Lebanon

\section{Correspondence to} Dr Rema A Afifi, Faculty of Health Sciences, Department of Health Promotion and Community Health, American University of Beirut, PO Box 11-0236 Riad El Solh, Beirut 1107 2020, Lebanon; ra15@aub.edu.lb

Received 25 September 2014 Accepted 30 December 2014 Published Online First 24 January 2015

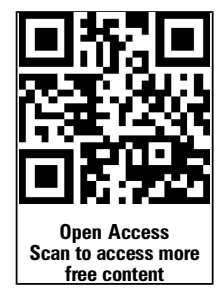

CrossMark

To cite: Akl EA, Ward KD, Bteddini $\mathrm{D}$, et al. Tob Control 2015;24:i13-i21.

\section{ABSTRACT}

Objective The objective of this narrative review is to highlight the determinants of the epidemic rise in waterpipe tobacco smoking (WTS) among youth globally. The Ecological Model of Health Promotion (EMHP) was the guiding framework for the review.

Data sources The following electronic databases were searched: Cochrane library, MEDLINE, EMBASE, PsycINFO, Web of Science and CINAHL Plus with Full Text. Search terms included waterpipe and its many variant terms.

Study selection Articles were included if they were published between 1990 and 2014, were in English, were available in full text and included the age group 10-29 years.

Data extraction Articles which analysed determinants of WTS at any of the levels of the EMHP were retained regardless of methodological rigour: 131 articles are included. Articles were coded in a standard template that abstracted methods as well as results.

Data synthesis The review found that methodologies used to assess determinants of WTS among youth were often conventional and lacked rigor: $3 / 4$ of the studies were cross-sectional surveys and most enrolled nonrepresentative samples. Within the framework, the review identified determinants of WTS at the intrapersonal, interpersonal, organisational, community and policy levels.

Conclusions The review suggests potential interventions to control WTS among youth, with emphasis on creative utilisation of social media, and tobacco control policies that include the specificities of WTS. The review further suggests the need for rigorous qualitative work to better contextualise determinants, and prospective observational and experimental studies that track and manipulate them to assess their viability as intervention targets.

\section{BACKGROUND}

Waterpipe tobacco smoking (WTS) is increasing worldwide. $^{1}{ }^{2}$ Once thought to be a form of tobacco use specific to the Eastern Mediterranean (EM) region, WTS has spread rapidly globally. ${ }^{34}$ Despite the rise of WTS starting in all age groups in the $1990 \mathrm{~s},{ }^{5}$ WTS is predominantly a youth behaviour. Youth rates of WTS exceed adult rates in almost every study conducted, as clearly described in the first paper in this issue on the 'Epidemiology of waterpipe smoking'. ${ }^{1}{ }^{2}$ Global statistics on ever and current WTS reveal alarming levels in high school and university students, often surpassing cigarette use. ${ }^{4}{ }^{6-8}$ WTS is not a safe alternative to cigarettes. Research indicates toxicant yields and adverse health effects equal to or worse than those for cigarettes. ${ }^{9-22}$ Recent comparisons of current e-cig versus WTS use among middle and high school students in the USA indicate equal rates for middle school students (1.1\%), and slightly higher rates of the latter in high school students. ${ }^{23}$

Early research and interventions that investigated health risk behaviours highlighted individual genetic background, knowledge and attitudes; however, in the 1970s, researchers began to document the critical influence of the social and physical environments. A variety of ecological models have been suggested. For the purposes of this review, the Ecological Model of Health Promotion (EMHP) ${ }^{24}$ was selected as a framework to guide the analysis. The EMHP posits that behaviour is influenced by factors at a variety of levels including intrapersonal, interpersonal, organisational/institutional, community and policy. Intrapersonal variables focus on an individual's knowledge, attitudes and beliefs. Interpersonal variables focus on the influences of parents, peers, siblings, teachers, health providers and others in relatively close contact with the individual. The organisational level describes how the context and structures of formal and informal institutions such as schools, hospitals and workplaces can support or hinder behaviour change. At the community level, influences such as social networks, neighbourhoods and mass media buffer or facilitate the effect of larger forces on the individual. Finally, policy can influence behaviour change by changing the underlying attitudes, motivations and social norms. The EMPH was selected as it incorporates the majority of variables that research has linked to behaviour, including substance use in general $^{25} 26$ and tobacco use in particular. ${ }^{27} 28$ Though determinants of tobacco use at each of these levels have been specifically identified for cigarettes, most of the WTS research has focused on intrapersonal or interpersonal determinants. The EMHP is relevant not only to research but also to practice and policy.

Although several narrative reviews of WTS have included sections on determinants of use, only one systematic review specific to motives, beliefs and attitudes around WTS has been published. ${ }^{29}$ None of the reviews have focused specifically on youth. None explored determinants based on a conceptual framework. In addition, none have specifically reviewed the methodologies applied in the research. Exploring the literature from this perspective allows for the comprehensive identification of 
what is known and what gaps still exist in our understanding of a particular behaviour, and the methods applied to this understanding, and thus guides research where needed, as well as interventions in practice and policy where evidence is clear. This paper does not focus on demographic or socioeconomic factors as those are reviewed in the Maziak et $a l^{2}$ paper in this issue.

\section{METHODS}

For this narrative review, the following electronic databases were searched: Cochrane library, MEDLINE, EMBASE, PsycINFO, Web of Science and CINAHL Plus with Full Text. Search terms included waterpipe and its many variant terms-hubble bubble, shisha, hooka, goza, arghile and narghile. The search was limited to papers published in English, between 1 January 1990 and 15 August 2014. We took 1990 as our lower limit based on the Rastam et $a l^{5}$ analysis of the rise in WTS among all age cohorts in the 1990s. Given that this epidemic is particularly concentrated among young people, we included only articles that included the age range 10-29 years. The articles abstracted were compared with those already available in a database of articles on tobacco use kept by the Public Health in the Arab World website as well as with the articles included in the earlier systematic review ${ }^{29}$-additional articles were included when missing.

The title and abstract of each selected article were read, and the article was retained if it discussed determinants of WTS, which included knowledge, beliefs, attitudes, motives, perceptions, as well as social, media-related and policy related factors. Since research on WTS determinants has increased only in the past decade, and since the objective of this review was to document any findings at each of the levels of the EMHP, we included articles regardless of methodological rigour. The total number of articles included in this review is 144 , including both quantitative and qualitative methods.

Articles were divided by country. Coauthors coded the articles in a template that abstracted methods as well as results. Of the 144 articles, 131 were data-based studies (not editorials, news analyses or reviews) and only these were included in the assessment of methods. Once data abstraction was complete, the articles (and their summaries in the template) were redistributed for narrative review to coauthors by the level of the EMHP.

\section{RESULTS}

\section{Review of the methodologies used in the research around WTS determinants}

A total of 131 data-based studies were identified. These included 22 qualitative, 107 quantitative and 2 mixed method (quantitative plus qualitative) studies. Qualitative methodologies included key informant interviews, focus groups, behavioural observation, and analysis of text-based and visual-based materials (eg, websites, advertisements, twitter posts and policy docuvast majority, 106 (97.2\%), used surveys; of these, 100 (94.3\%) were cross-sectional, and 6 utilised prospective designs. The quantitative studies also included one that used a lab-based experimental design, and another that assessed waterpipe use and topography characteristics using behavioural observation.

In terms of sampling methodology, 9 of the 131 studies sampled archival materials (text or visual documents) and 123 used human subjects (one was a mixed methods study that sampled both individuals and archival data). Of the 123 studies that sampled individuals, 73 sampled either randomly or assessed entire populations, whereas 50 used convenience ments). Of the 109 quantitative and mixed methods studies, the

sampling. Among these 123 studies, a majority of sampling frames were educational institutions $(n=75), 19$ were community-based samples including healthcare clinics, 15 used multiple frames (typically combinations of educational institutions, cafes, worksites and healthcare institutions), 8 were cafes/ restaurants where waterpipe users congregate and 5 were national samples.

Among the 123 studies that used human subjects, 47 (35.9\%) were not representative of specific populations. The other 76 used random sampling or assessed entire populations to obtain representative samples from nations $(n=4)$, city, state or region $(n=10)$, school system or single educational institution $(n=53)$, waterpipe customers in a retail establishment (eg, café; $n=4$ ), and other populations (eg, pregnant women in healthcare settings; $\mathrm{n}=5$; table 1 ).

\section{Review of factors affecting the rise in WTS: applying the EMHP for analysis}

The vast majority of the 131 data-based studies globally focused on either the intrapersonal or interpersonal levels (table 2) and were conducted in the Arab region or the USA. When analysed by 5 -year intervals, it is clear that as knowledge evolved and progressed, more attention was placed on understanding factors at the more distal levels such as organisational, community and

Table 1 Methodological characteristics of data-based studies included in review $(\mathrm{N}=131)$

\begin{tabular}{|c|c|}
\hline & n (\%) \\
\hline \multicolumn{2}{|l|}{ Method } \\
\hline Quantitative & $107(81.7)$ \\
\hline Qualitative & $22(16.1)$ \\
\hline Mixed methods (quantitative and qualitative) & $2(1.5)$ \\
\hline \multicolumn{2}{|l|}{ Design } \\
\hline Analysis of text or visual materials & $9(6.9)$ \\
\hline Key informants & $2(1.5)$ \\
\hline Focus groups & $6(4.6)$ \\
\hline Other qualitative design & $5(3.8)$ \\
\hline Cross-sectional survey & $100(76.3)$ \\
\hline Prospective survey & $6(4.6)$ \\
\hline Experimental design & $1(0.8)$ \\
\hline Other quantitative design & $1(0.8)$ \\
\hline \multicolumn{2}{|l|}{ Sampling methodology* } \\
\hline Convenience sample assessed & $50(38.2)$ \\
\hline Entire population or a random sample assessed & $73(55.7)$ \\
\hline Archival data assessed & $9(6.9)$ \\
\hline \multicolumn{2}{|l|}{ Sampling frame } \\
\hline Educational institution & $75(57.3)$ \\
\hline Café/restaurant & $8(6.1)$ \\
\hline Local community, including health clinics & $19(14.5)$ \\
\hline National & $5(3.8)$ \\
\hline Multiple frames & $15(11.5)$ \\
\hline Archival data & $9(6.9)$ \\
\hline \multicolumn{2}{|l|}{ Representativeness of human samples $(n=111)$} \\
\hline Not representative & $47(35.9)$ \\
\hline Representative of the population of a city, state or region & $10(7.6)$ \\
\hline Representative of the population of a nation & $4(3.1)$ \\
\hline Representative of a school system or educational institution & $53(40.5)$ \\
\hline Representative of waterpipe customers in a retail establishment & $4(3.1)$ \\
\hline Representative of other populations & $5(3.8)$ \\
\hline
\end{tabular}


Table 2 Data-based studies by level of the Ecological Model of Health Promotion and world region*

\begin{tabular}{|c|c|c|c|c|c|c|}
\hline Ecological model level & Arab region & Americas & Europe & Africa & Asia & Global \\
\hline Intrapersonal & $\mathrm{N}=23$ & $\mathrm{~N}=48$ & $\mathrm{~N}=5$ & & $\mathrm{~N}=6$ & $\mathrm{~N}=1$ \\
\hline Interpersonal & $\mathrm{N}=38$ & $\mathrm{~N}=35$ & $\mathrm{~N}=1$ & $\mathrm{~N}=2$ & $\mathrm{~N}=10$ & $\mathrm{~N}=1$ \\
\hline Institutional/organisational & $\mathrm{N}=4$ & $\mathrm{~N}=4$ & & & & $\mathrm{~N}=1$ \\
\hline Community & $\mathrm{N}=4$ & $\mathrm{~N}=5$ & & & $\mathrm{~N}=1$ & \\
\hline Policy & $\mathrm{N}=3$ & $\mathrm{~N}=7$ & $\mathrm{~N}=2$ & & & \\
\hline
\end{tabular}

policy levels (table 3). Policy-level studies have only recently begun to be conducted, despite a clear understanding (from decades of work related to the cigarette epidemic) of the need for comprehensive policy to impact tobacco control.

\section{Intrapersonal factors}

There are a number of intrapersonal factors affecting the epidemic rise in WTS among youth globally. These include reasons for smoking, attitudes towards WTS, perceptions about health hazards, perceptions of addictive properties and ability to quit.

\section{Reasons for smoking}

The most common reasons that youth provide for smoking a waterpipe are for entertainment, relaxation, to fill up free time (boredom/loneliness/absence of alternative recreation), out of curiosity, to socialise and to experiment with something new. ${ }^{68-86}$ They also use it as a mechanism for emancipation and an expression of manhood. ${ }^{78} 8788$ The waterpipe is also perceived to provide a positive somatic experience that engages almost all the senses, including taste, ${ }^{16} 69708589$ smell, $^{70} 8589$ sight, sound and touch. ${ }^{13} 78839091$ The combination of fruit flavour and smooth smoke was perceived to provide a 'relaxing appeal'. 92

'Culture' is often given as a reason for WTS use among EM young people living both inside and outside the EM region. ${ }^{93}$ For those living abroad, they claim it as one way to hang onto one's heritage, as well as to meet and socialise with others of the same ethnicity. ${ }^{9} 83$

\section{Attitudes towards WTS}

Youth have favourable perceptions towards WTS, and describe it as entertaining, attractive, romantic, fun, highly popular, socially acceptable, fashionable, exotic, intimate and an 'affordable

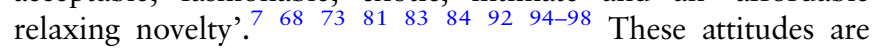

Table 3 Data-based studies by level of the Ecological Model of Health Promotion and year*

\begin{tabular}{|c|c|c|c|}
\hline Ecological model level & $2000-2004^{* *}$ & 2005-2009 & 2010-2014 \\
\hline Intrapersonal & $\mathrm{N}=6$ & $\mathrm{~N}=25$ & $\mathrm{~N}=47$ \\
\hline Interpersonal & $\mathrm{N}=6$ & $\mathrm{~N}=21$ & $\mathrm{~N}=66$ \\
\hline Institutional/organisational & & $\mathrm{N}=2$ & $\mathrm{~N}=8$ \\
\hline Community & $\mathrm{N}=3$ & $\mathrm{~N}=3$ & $\mathrm{~N}=10$ \\
\hline Policy & & & $\mathrm{N}=12$ \\
\hline \multicolumn{4}{|c|}{$\begin{array}{l}\text { *The total } \mathrm{N} \text { is greater than } 131 \text { as several articles include more than one level. The } \\
\text { level of each of the data-based articles is listed in the reference list. References }{ }^{30-67} \\
\text { were coded as part of the methodological analysis but not referenced directly in the } \\
\text { text. } \\
{ }^{* *} \text { Although this review abstracted articles starting in } 1990 \text {, no articles exploring WTS } \\
\text { determinants were found prior to the year } 2000 \text {. }\end{array}$} \\
\hline
\end{tabular}

associated with WTS use as well as intention to initiate use among non-users. ${ }^{99} 100$ In one study, thinking that successful and cool people smoke waterpipe-sometimes called imitation -increased the odds of being a current WTS. ${ }^{69} 101$ More notably, the youth view the waterpipe apparatus itself as attractive. ${ }^{70}$ Youth also perceive that WTS results in a number of positive affective and cognitive effects, including relieving anxiety and stress, ${ }^{102-104}$ anger and depression; ${ }^{71}$ forgetting problems, ${ }^{87}$ and improving concentration and self-efficacy. On the other hand, self-efficacy and self-esteem-both attitudinal-were found to be protective against WTS. ${ }^{99}$

Young people often compare the waterpipe to cigarettes. The waterpipe is perceived to be a more 'attractive' tobacco product that is more appealing than cigarettes, is novel, has secondhand smoke that is less bothersome, is more available and accessible, and is a cheaper alternative to an expensive night out at bars. $^{75} 7892105$ Some view the waterpipe as a replacement or exit strategy from cigarettes. ${ }^{69} 92$

\section{Perceptions about health hazards}

A survey of US undergraduate students found that the majority believed there were health hazards associated with waterpipe use. $^{82}$ As to the perceived health hazards of WTS relative to cigarettes, results of published surveys are inconclusive. ${ }^{29}$ Most studies conducted in EM countries, ${ }^{69} 737494106-109$ and a few in Western ${ }^{76} 911^{110-115}$ and other ${ }^{116-118}$ countries, found that youth believe that WTS is less harmful than cigarette smoking. However, a substantive number of other studies found the opposite. $^{16859597119-124}$ Identified reasons for the perceptions of lower harms with WTS include water filtration, little or no nicotine, fewer chemicals, social acceptability, fruit flavours (and their aromatic smell) that are perceived to indicate a healthy product or safe detoxified smoke, and the lack of media campaigns about WTS implying that they must be safer. $^{72} 747589102106111125126$

\section{Perception of addictive properties and ability to quit}

Typically, youth report a low or no chance of becoming addicted to WTS.72 75102110126 Similarly, those who use a waterpipe typically report a high degree of confidence that they can quit at any time. ${ }^{75} 82102112126$ One study in Syria reported that the majority of WTS believed quitting smoking is difficult. ${ }^{123}$ When speaking about addiction, youth point to the frequency of smoking, as well as smoking alone as indicators. ${ }^{102}$

\section{Interpersonal influences}

The social aspect is perhaps the 'sine qua non' of WTSbinding users to the experience and providing 'kinship' or 'brotherhood' and encouraging use. ${ }^{72} 779295$ 127-129 Family and friends ${ }^{69}$ play an important role in WTS-either encouraging or discouraging its use. ${ }^{100} \mathrm{Up}$ to $90 \%$ of university 
students in the USA and over 2/3 of 13-19 year-olds in Beirut, Lebanon indicated that they first tried WTS with family or friends. ${ }^{75} 124$ Despite the fact that smokers agreed that the WTS 'set-up' was burdensome, they felt that almost any form of planning for social interaction required preparation time, and was therefore a necessary commitment. ${ }^{77}$

\section{Peer influences}

Peer WTS use and encouragement/pressure from peers to use WTS seem to be powerful influences on initiation and continued smoking. ${ }^{69-72}$ 74-76 79828599114115120124 129-135 Across different neighbourhoods in Beirut, the only consistent variable influencing current WTS was peer encouragement. ${ }^{124}$ In support of peer influence, and in contrast, "having friends who disagree with smoking was correlated with lower WP smoking". 136

\section{Parental influences}

Family members were identified as another influential factor in WTS $^{69} 7576109134135137$ both in initiation of use and in continued use at home and in social gatherings. ${ }^{85} 87$ Having a mother and/or father who smoked a waterpipe was associated with youth WTS. ${ }^{99} 114124129130132138$ Families can also discourage its use. In a study from San Francisco, the majority $(61 \%)$ of parents who knew about their children's use of the waterpipe disapproved of it. ${ }^{85}$

\section{Organisational/institutional influences}

Curricular requirements are often one aspect of organisational influences. The Global Youth Tobacco Survey (GYTS) asks a question about exposure to education about smoking in the curriculum. This question is usually a general question and not specific to the waterpipe. In 2011, the Lebanon GYTS asked specifically about whether students had been taught about the dangers of WTS, and whether they had discussed the reasons why people their age smoke waterpipes. Results indicated that $42.0 \%$ of students had been taught about the dangers of WTS in school, yet only $30.6 \%$ had discussed the reasons why people their age smoked a waterpipe.

Surveys of prevalence of WTS among health professional students also indicate inadequate knowledge, ${ }^{139-141}$ and high rates of use. ${ }^{123} 139$ 142-145 These misperceptions and behaviour resulted in health professional students encouraging others to smoke the waterpipe and intending to smoke it themselves in the future. ${ }^{140} 143$ In addition, health professional students often are not exposed in the curricula to information about tobacco use, particularly WTS, and methods of smoking cessation. ${ }^{144} 146$ This suggests that curricula of health profession schools may also be falling short of transmitting critically needed information on this epidemic to key health personnel.

Another aspect of organisational support is the availability of clinical prompts to ask about WTS smoking status during each and every consultation visit, especially with young adults. ${ }^{147}$ Clinical guidelines around tobacco use, including the 5As, are applied to cigarette smoking, but rarely to WTS.

Organisational influences also include the commercial 'pull' factors that encourage WTS. Young people have indicated that the easy availability, affordability and innovations in waterpipe apparatus designs and flavours encourage their use. ${ }^{148}$ The availability of commercial waterpipe venues around university campuses also encourages WTS, and home delivery has boosted waterpipe use in recent years. ${ }^{112} 148$
Community level influences

Research points to the normative acceptability of WTS, ${ }^{95} 111149$ even in societies where cigarette smoking is seen to be inappropriate for women. ${ }^{88}$ Being perceived as closer to the local traditions/culture, WTS may escape the societal taboos of cigarette smoking by women. ${ }^{16}$ In Western countries, surveys of young people indicate $60-95 \%$ of respondents stating that WTS is very socially acceptable, and is perhaps the most socially acceptable form of tobacco, with projections of increased popularity in the next 5 years. ${ }^{75}$ In the EM region, the extent of social acceptability of waterpipe smoking appears to vary by country. In Syria and Pakistan, family attitudes towards WTS were mostly either neutral or positive, particularly compared with cigarette smoking, ${ }^{16} 74150$ though some point to the religious unacceptability of WTS. ${ }^{78}$ In contrast, respondents from Lebanon and Egypt mostly felt that family members disapproved of WTS. $^{87} 108$

Several studies have looked at the mass media environment surrounding young people in relation to WTS, particularly in the USA. Advertisements for waterpipes on internet websites as well as social media sites such as YouTube, and print newspapers, have been analysed to assess the focus of messages being promoted. $^{72}{ }^{151-153}$ Several key themes cut across the newspaper and website analysis: (1) the websites target young consumers by emphasising the 'opportunity to be part of a global youth culture' (ref. 72, p. 127); (2) the images associated with WTS include sociability, entertainment, relaxation, pleasure, sensuality and harm reduction; and (3) most advertisements and websites do not include the word 'tobacco' when discussing WTS, and health warnings are rare. $^{72} 151 \quad 153$ WTS smoking advertisements in Lebanon depict sensuous modern women enjoying a waterpipe. Weight concerns of young women also are targeted through promotion of 'diet hookah'. ${ }^{154}$ The 'healthy' aspects of smoking a waterpipe are further suggested in advertisements through its association with fruit. ${ }^{155}$ Across advertisements in newspapers or websites, indicators of quality were highlighted whether through linkages to words such as 'untouched by human hands' or 'eco-friendly' or through an explicit mention of product 'quality'. When comparing YouTube videos on cigarettes or waterpipes, those focused on the latter were less likely to depict smoking negatively or to include a discussion of the short-term or long-term health effects, and were equally likely to depict smoking (of either product) as attractive, sexual, sociable, powerful and exotic. A study in Lebanon found an association between increasing internet usage/week and WTS. $^{132}$

Other qualitative research has reported on perceptions of young people-both waterpipe tobacco smokers and nonsmokers-about media influences on WTS. ${ }^{78}$ Focus group participants noted the image of waterpipe smoking promoted by the media to be glamorous, sexy and cool.

\section{Policy influences on WTS}

With the spread of WTS, attention of public health advocates to policies governing their use has grown. Analyses-from various countries of the world-have focused on laws recommended by the Framework Convention on Tobacco Control (FCTC), the first global health treaty, ratified by 179 countries worldwide. Results suggest that current tobacco control legislation may inadequately cover WTS. ${ }^{72}{ }^{156-160}$ In a review of regulations in seven countries around the world, ${ }^{125}$ India and Pakistan were found to have the most effective regulations to control waterpipe tobacco smoking. In an analysis of availability of clean air 
regulations in 100 large US cities, ${ }^{156}$ Primack et al found that only $4 \%$ clearly had regulations which seem to include WTS, despite the proliferation of 'hookah' bars since $2000 .^{125}{ }^{159} \mathrm{In}$ addition, regulations in the USA and the EU exempt the flavoured moassel waterpipe tobacco, and include taxes on waterpipe tobacco that are lower than those on cigarettes. ${ }^{158} 159161$ A review of warning labels on a sample of waterpipe tobacco products and related accessories from Lebanon and other countries found all the countries to be non-compliant with FCTC article $11 .^{153}$ A recent thesis documented the positive impact of waterpipe-specific warnings on knowledge and quit intentions. ${ }^{162}$ Regulation of prices-one of the most effective policies to curb tobacco use-is also less stringent with waterpipes than cigarettes, at least in the USA. ${ }^{163}$ The impact on youth WTS of policies that control the location of waterpipe cafes in evident in a recent finding that indicate that students attending schools in neighborhoods with a higher density of of such cafes were less likely to be waterpipe tobacco smokers than student attending schools in neighborhoods with fewer such cafes. ${ }^{99}$

Research has also reported on perceptions of young people vis-à-vis WTS legislation. ${ }^{148}{ }^{164}$ Participants in focus group discussions in Lebanon and England noted the importance of legislation in curbing WTS among young persons and stated that the different approaches of governments in legislating cigarettes versus waterpipes promote the idea that one is a safer alternative than the other. They also cautioned that the passage of a law is only the first step. Effective implementation and enforcement is key. Differences in coverage and application of tobacco control laws to cigarettes and waterpipe may limit comprehensive tobacco control efforts as individuals may merely shift their smoking patterns from one tobacco product to another. ${ }^{164}$

\section{DISCUSSION}

Research and publications are increasing globally around WTS. ${ }^{165}$ However, a recent comparison with e-cigs indicates that WTS scholarship is lagging behind. ${ }^{166}$ Given the rising prevalence of WTS among young persons globally and the identified health effects, continued vigilance is critical. A variety of research areas around epidemiology and health effects have been suggested in articles in this issue. This review provides guidance for the development of targeted interventions (including policy) to prevent WTS.

Within a socioecological framework, the review has identified determinants of WTS at the intrapersonal, interpersonal, organisational, community and policy levels. While previous reviews have pointed to knowledge, beliefs and attitudes-as well as social factors-as key drivers of WTS, they often did not tackle the wider issues and structure their analysis within a conceptual framework. Doing so allows a comprehensive understanding of the multitude of factors influencing youth use. Indeed, our findings clearly point to the complex web of causation leading to increasing rates of youth WTS initiation and progression globally. The understanding of this web should lead to the development of comprehensive interventions which target both the proximal and distal causes of youth use. This is in line with the FCTC, the M-POWER report of the $\mathrm{WHO}^{167}$ and the recently released 'Best practices for comprehensive tobacco control programs' that states: "A comprehensive statewide tobacco control program is a coordinated effort...(that) combines educational, clinical, regulatory, economic, and social strategies (ref. 168, p. 6)."

This current review of determinants of WTS follows the first review of WTS after a decade. ${ }^{169}$ That review stated that "very few studies have investigated attitudes and beliefs towards waterpipe use" (p. 329), whereas the current review has identified over 80 studies globally that tackle these concepts with reference to youth (table 3 ). In addition, over the past decade and particularly in the past 5-year interval (2010-2014), researchers have begun to investigate the broader levels of influence on WTS by young persons. Whereas most of the research remains quantitative in nature, qualitative studies are beginning to unpack the context around which WTS occurs (table 1).

On the basis of the findings of this review, the remainder of the discussion will highlight some necessary steps forward to control this global epidemic of WTS among youth.

At the intrapersonal level, interventions need to focus on enhancing knowledge and shifting attitudes. Social media is a popular mechanism of communication of this generation, and public health professionals should learn to make use of it effectively. Twitter and Facebook posts have been used to assess key themes discussed around use of waterpipes and e-cigs. ${ }^{170} 171$ The number of hours of internet use per week was associated with WTS, suggesting that media messages transmitted through this medium have a powerful impact on behaviour. An internetbased experimental study demonstrated that providing university students brief information about the harms of waterpipe smoking increased the perceived risk and worry about harm and addiction, as well as the desire to quit. ${ }^{70}$ Creative techniques such as these can also be used in promoting prevention, and in counter-advertisements. The messages sent by tobacco control advocates need to be as attractive and appealing as those sent by the pro-tobacco machinery. The Legacy Foundation has recently used YouTube to distribute key information around WTS. ${ }^{172}$ Engaging youth in the development of these types of media messages will ensure that they are in line with the technology and images of the new generation.

The interpersonal and organisational levels interact in interventions to prevent WTS. Parents, teachers and schools need to be engaged. ${ }^{72}$ School policies prohibiting smoking on school premises must be implemented. Anecdotal evidence indicates that in some countries, WTS is allowed on school trips, and indeed is a shared experience between teachers and students. Parents should be engaged early and educated about the adverse health and dependence-producing features of WTS (see reviews of these areas in this issue). ${ }^{2} 12173174$ Primary care health providers as well as dentists must be engaged in the promotion. Health professions schools curricula should include clear information on the hazards of WTS, as well as general tips for smoking cessation. In addition, smoking cessation services must be made available, accessible and affordable at the primary care level. A main reason for WTS stated by young people was the feeling of boredom or needing to fill time. At the community level, alternative sources of recreation need to be created to engage young people creatively and effectively when they are out of school. ${ }^{175}$

The FCTC has identified evidence-based policies to control tobacco use. ${ }^{17}$ Though the convention covers all forms of tobacco use, its practical applications have focused most on cigarettes, leaving wide gaps in the development and implementation of alternative tobacco products. As succinctly stated by Jawad et al, ${ }^{176}$ "Worryingly, the waterpipe industry including waterpipe cafes, operates in a almost completely unregulated market." FCTC protocols and guidelines need to be developed to include WTS specificities. ${ }^{72}$ Examples include-at a minimum-critically analysing the placement of warnings of tobacco products and accessories, ensuring that clean indoor air laws are not exempting waterpipe establishments, extending the ban on flavoured tobacco to include waterpipes, and increasing taxes on waterpipe products and accessories. 
This review also highlights some important limitations in our understanding of the determinants of WTS by youth. In particular, the rather limited breadth and rigour of methodologies that have been used to assess determinants within the socioecological framework limit our ability to intervene effectively on this public health problem. Three-fourths of the studies included in this review were cross-sectional survey studies. Only six prospective observational studies and one experimental study were identified. The problems with relying on observational data to guide selection of determinants to target in theory-based interventions are well known. ${ }^{177}$ Further, most studies enrolled small, geographically restricted (eg, single school or city) and/or non-representative samples, possibly limiting the generalisability of the findings. Our ability to prevent WTS would be enhanced by both rigorous qualitative work to better contextualise its determinants, as well as prospective observational and experimental studies that track and manipulate suspected determinants to assess their viability as intervention targets.

There were few preventive intervention/evaluation studies related to WTS that were found in our literature search. Despite the limitations of methods used to date, scholarship is advanced enough to move towards the testing of interventions to prevent or delay the uptake of WTS, as well as to encourage cessation. Developing, implementing and evaluating interventions is a critical area for future research and practice. For example, suggested pictorial warnings for waterpipe tobacco products and accessories have been developed and should continue to be tested for effectiveness. ${ }^{157}$ These interventions can and should span all levels of the ecological model.

\section{What this paper adds}

- Waterpipe tobacco smoking (WTS) is rising globally, particularly among young people.

- WTS is not a safe alternative to cigarettes. Its health effects are similar to or worse than those of cigarettes.

- A recent systematic review of motives, beliefs and attitudes found positive perceptions towards WTS, amid strong social acceptability and encouragement of its use.

- The published literature to date tends to focus mostly on determinants at the individual level, extending to peer and parent influences.

- A comprehensive analysis of determinants at ecological levels is missing.

- Despite the increasing prevalence of WTS among youth globally, no review has specifically focused on this age group.

- The methodological rigour of the published articles has not been systematically assessed as yet.

- The review was guided by the Ecological Model of Health Promotion as a framework for abstraction, analysis and conclusion. Within the framework, the review identified determinants of WTS at the intrapersonal, interpersonal, organisational, community and policy levels.

- The review found limited breadth and rigour of methodologies used to assess determinants of WTS among youth, and makes recommendations to strengthen the evidence base.

- Potential foci for intervention to control youth WTS are highlighted within the comprehensive framework.
The WHO mantra of 'Make the healthy choice the easy choice' is apt for the assessment of the extent to which public health approaches have effectively tackled WTS. Success would be achievable when the threads within the complex webs of causation have been severed, so that young people are surrounded by environments that promote a choice of non-smoking more easily than smoking. Two global efforts in tobacco control-the FCTC and the MPOWER toolkit ${ }^{167}$ - both promote an ecological approach with suggested interventions at each of the EMHP levels. The public health community must always be looking ahead: "...Just as industry innovates in approaches to promotion, so must the public health community, seeking out new media, word of mouth, and organization-based efforts to reach young adults before they initiate use and to support cessation."

This review was framed within the EMHP. Although more comprehensive than previous reviews, it still ignores the levels of influence beyond state/national policy. Critical analysis of global health efforts have clearly indicated the impact of global economic and trade policies as well as competing health policies in achieving impact in any one area. ${ }^{178} 179$ "We are challenged to develop a public health approach that responds to the globalised world. The present global health crisis is not primarily one of disease, but of governance..." 180

Correction notice This article has been corrected since it was published Online First. The middle initial has been added to author ' $E$ Akl', and the spelling of author 'T Loufti' has been amended to 'T Lofti'.

Twitter Follow Rima Afifi at @rima_ra15

Contributors RAA and EA conceptualised the manuscript. DB and RK abstracted the articles. KDW led the methodological review. All authors read and coded the articles, and analysed and wrote summaries of the results. RAA compiled these summaries and took the lead in writing the draft manuscript. All authors edited the draft, as well as read and approved the final version.

\section{Competing interests None.}

Provenance and peer review Commissioned; externally peer reviewed.

Open Access This is an Open Access article distributed in accordance with the Creative Commons Attribution Non Commercial (CC BY-NC 4.0) license, which permits others to distribute, remix, adapt, build upon this work non-commercially, and license their derivative works on different terms, provided the original work is properly cited and the use is non-commercial. See: http://creativecommons.org/ licenses/by-nc/4.0/

\section{REFERENCES}

References linked to data-based articles (included in table 1) are identified by level(s) of the EMHP tackled. The legend for this identification is as follows: $A=$ intrapersonal level, $B=$ interpersonal level, $C=$ institutional/organisational level, $D=$ community level, $E=$ policy level.

1 AkI EA, Gunukula SK, Aleem $S$, et al. The prevalence of waterpipe tobacco smoking among the general and specific populations: a systematic review. $B M C$ Public Health 2011;11:244.

2 Maziak W, Ben Taleb Z, Bahelah R, et al. The Global Epidemiology of waterpipe tobacco smoking. Tob Control 2015;24:i3-12.

3 Bowman J. Time to smell the sweet smoke: fantasy themes and rhetorical vision in nargile cafe cultures. J Pop Cult 2009;42:442-57.

4 Maziak W. The global epidemic of waterpipe smoking. Addict Behav 2011;36:1-5.

5 Rastam S, Ward KD, Eissenberg $T$, et al. Estimating the beginning of the waterpipe epidemic in Syria. BMC Public Health 2004;4:32. (D)

6 Warren CW, Lea V, Lee J, et al. Change in tobacco use among 13-15 year olds between 1999 and 2008: findings from the Global Youth Tobacco Survey. Glob Health Promot 2009;16(2 suppl):38-90.

7 Grekin ER, Ayna D. Waterpipe smoking among college students in the United States: a review of the literature. J Am Coll Health 2012;60:244-9.

8 Barnett TE, Smith T, He Y, et al. Evidence of emerging hookah use among university students: a cross-sectional comparison between hookah and cigarette use. BMC Public Health 2013;13:302. (A)

9 Chan A, Murin S. Up in smoke: the fallacy of the harmless Hookah. Chest 2011;139:737-8.

10 Bou Fakhreddine HM, Kanj AN, Kanj NA. The growing epidemic of water pipe smoking: Health effects and future needs. Respir Med 2014;108:1241-53. 
11 Aslam HM, Saleem S, German S, et al. Harmful effects of shisha: literature review. Int Arch Med 2014;7:16.

12 El Zaatari ZM, Chami HA, Zaatari GS. Health effects associated with waterpipe smoking. Tob Control, in review.

13 Dar-Odeh NS, Abu-Hammad OA. The changing trends in tobacco smoking for young Arab women; narghile, an old habit with a liberal attitude. Harm Reduct J 2011;8:24

14 Akl EA, Gaddam S, Gunukula SK, et al. The effects of waterpipe tobacco smoking on health outcomes: a systematic review. Int J Epidemiol 2010;39:834-57.

15 Cobb C, Ward KD, Maziak W, et al. Waterpipe tobacco smoking: an emerging health crisis in the United States. Am J Health Behav 2010;34:275-85.

16 Maziak W, Eissenberg T, Rastam S, et al. Beliefs and attitudes related to narghile (waterpipe) smoking among university students in Syria. Ann Epidemiol 2004; 14:646-54. (A,B)

17 WHO. World Health Organisation Framework Convention on Tobacco Control. Geneva, Switzerland, 2003.

18 Radwan G, Hecht SS, Carmella SG, et al. Tobacco-specific nitrosamine exposures in smokers and nonsmokers exposed to cigarette or waterpipe tobacco smoke. Nicotine Tob Res 2013:15:130-8.

19 Eissenberg T, Shihadeh A. Waterpipe tobacco and cigarette smoking: direct comparison of toxicant exposure. Am J Prev Med 2009:37:518-23.

20 Maziak W, Rastam S, Ibrahim I, et al. CO exposure, puff topography, and subjective effects in waterpipe tobacco smokers. Nicotine Tob Res 2009:11:806-11.

21 Jawad M, McEwen A, McNeill A, et al. To what extent should waterpipe tobacco smoking become a public health priority? Addiction 2013;108:1873-84.

22 Shihadeh A, Saleh R. Polycyclic aromatic hydrocarbons, carbon monoxide, "tar", and nicotine in the mainstream smoke aerosol of the narghile water pipe. Food Chem Toxicol 2005;43:655-61.

23 Centers for Disease Control and Prevention. Tobacco use among middle and high school students-United States, 2000-2009. MMWR Morb Mortal Wkly Rep 2010:59:1063.

24 McLeroy KR, Bibeau D, Steckler A, et al. An ecological perspective on health promotion programs. Health Educ Q 1988;15:351-77.

25 Sorensen G, Barbeau E, Hunt MK, et al. Reducing social disparities in tobacco use: a socio-contextual model for reducing tobacco use among blue-collar workers. Am I Public Health 2004;94:230-9.

26 Dickson LM, Derevensk JL, Gupta R. The prevention of gambling problems in youth: a conceptual framework. J Gamb/ Stud 2002;18:97-159.

27 Fong GT, Cummings KM, Borland R, et al. The conceptual framework of the International Tobacco Control (ITC) Policy Evaluation Project. Tob Control 2006;15 (Suppl III):iii3-11.

28 Tyas SL, Pederson LL. Psychosocial factors related to adolescent smoking: a critical review of the literature. Tob Control 1998;7:409-20.

29 Akl EA, Jawad M, Lam WY, et al. Motives, beliefs and attitudes towards waterpipe tobacco smoking: a systematic review. Harm Reduct J 2013;10:12.

30 Al Moamary MS, Al Ghobain MA, Al Shehri SN, et al. The prevalence and characteristics of water-pipe smoking among high school students in Saudi Arabia. J Infect Public Health 2012;5:159-68. (A)

31 Alzohairy MA. Water pipe \& cigarette smoking among Qassim university male students: prevalence and beliefs. Int J Health Sci 2012;6:45. (A)

32 Alzyoud S, Weglicki LS, Kheirallah KA, et al. Waterpipe smoking among middle and high school Jordanian students: patterns and predictors. Int J Environ Res Public Health 2013;10:7068-82. (A)

33 Amrock SM, Gordon T, Zelikoff JT, et al. Hookah use among adolescents in the United States: results of a national survey. Nicotine Tob Res 2014;16:231-7. (A,B)

34 Azab M, Khabour OF, Alzoubi KH, et al. Exposure of pregnant women to waterpipe and cigarette smoke. Nicotine Tob Res 2013;15:231-7. (A)

35 Baker OG, Rice V. Predictors of narghile (water-pipe) smoking in a sample of American Arab Yemeni adolescents. J Transcult Nurs 2008;19:24-32. (A,B)

36 Dar-Odeh N, Abu-Hammad O, Al-Abdalla M, et al. Narghile smoking among Jordanian educated working women: attitudes and beliefs. $\mathrm{Br} J$ Med Med Res 2013:3:483-90. (A)

37 El-Roueiheb Z, Tamim H, Kanj M, et al. Cigarette and waterpipe smoking among Lebanese adolescents, a cross-sectional study, 2003-2004. Nicotine Tob Res 2008;10:309-14. (B)

38 Fielder RL, Carey KB, Carey MP. Prevalence, frequency, and initiation of hookah tobacco smoking among first-year female college students: a one-year longitudinal study. Addict Behav 2012;37:221-4. (A)

39 Freiberg MJ. Federal approaches to the regulation of noncigarette tobacco products. Am J Prev Med 2012;43:S249-54. (E)

40 Hampson SE, Tildesley E, Andrews JA, et al. Smoking trajectories across high school: sensation seeking and hookah use. Nicotine Tob Res 2013;15:1400-8. (B)

41 Jordan HM, Delnevo CD. Emerging tobacco products: hookah use among New Jersey youth. Prev Med 2010;51:394-6. (B)

42 Khabour OF, Alzoubi KH, Eissenberg T, et al. Waterpipe tobacco and cigarette smoking among university students in Jordan. Int J Tuberc Lung Dis 2012;16: 986. (A)
43 Korn L, Harel-Fisch Y, Amitai G. Social and behavioural determinants of nargila (water-pipe) smoking among Israeli youth: findings from the 2002 HBSC survey. J Subst Use 2008;13:225-38. (A)

44 Korn L, Magnezi R. Cigarette and nargila (water pipe) use among Israeli Arab high school students: prevalence and determinants of tobacco smoking. Sci World J 2008:8:517-25. (A)

45 Lee YO, Bahreinifar S, Ling PM. Understanding tobacco-related attitudes among college and noncollege young adult hookah and cigarette users. J Am Coll Health 2013;62:10. (C)

46 Musmar S. Smoking habits and attitudes among university students in Palestine: a cross-sectional study. EMHJ 2012;18:454-60. (A)

47 Nuzzo E, Shensa A, Kim KH, et al. Associations between hookah tobacco smoking knowledge and hookah smoking behavior among US college students. Health Educ Res 2013;28:92-100. (A)

48 Richter $\mathrm{P}$, Caraballo R, Pederson LL, et al. Exploring use of nontraditional tobacco products through focus groups with young adult smokers, 2002. Prev Chronic Dis 2008:5:A87. (A,B)

49 Richter PA, Pederson LL, O'Hegarty MM. Young adult smoker risk perceptions of traditional cigarettes and nontraditional tobacco products. Am J Health Behav 2006;30:302-12. (A)

50 Roohafza H, Sadeghi M, Shahnam M, et al. Social norms of cigarette and hookah smokers in Iranian universities. ARYA Atheroscler 2013:9:45. (A)

51 Sabahy A-R, Divsalar K, Nakhaee N. Attitude of university students towards waterpipe smoking: study in Iran. Addict Health 2011:3:9. (A)

52 Sterling KL, Mermelstein R. Examining hookah smoking among a cohort of adolescent ever smokers. Nicotine Tob Res 2011;13:1202-9. (B)

53 Amin TT, Amr M, Zaza BO, et al. Harm perception, attitudes and predictors of waterpipe (shisha) smoking among secondary school adolescents in Al-Hassa, Saudi Arabia. Asian Pac J Cancer Prev 2010;11:293-301. (A)

54 Haroon M, Munir A, Mahmud W, et al. Knowledge, attitude, and practice of water-pipe smoking among medical students in Rawalpindi, Pakistan. J Pak Med Assoc 2014:64:155-8. (A)

55 Maziak W, Fouad F, Asfar T, et al. Prevalence and characteristics of narghile smoking among university students in Syria. Int J Tuberc Lung Dis 2004;8:882-9. $(A, B)$

56 Asfar T, Ward KD, Eissenberg T, et al. Comparison of patterns of use, beliefs, and attitudes related to waterpipe between beginning and established smokers. $B M C$ Public Health 2005;5:19. (A,B)

57 Ward KD, Hammal F, VanderWeg MW, et al. Are waterpipe users interested in quitting? Nicotine Tob Res 2005;7:149-56. (A,B)

58 Primack $\mathrm{BA}$, Fertman $\mathrm{Cl}$, Rice $\mathrm{KR}$, et al. Waterpipe and cigarette smoking among college athletes in the United States. J Adolesc Health 2010;46: 45-51.(A,B)

59 Noonan D, Kulbok P, Yan G. Intention to smoke tobacco using a waterpipe among students in a southeastern US college. Public Health Nurs 2011;28:494-502. (A,B)

60 Mzayek F, Khader Y, Eissenberg T, et al. Patterns of water-pipe and cigarette smoking initiation in schoolchildren: Irbid longitudinal smoking study. Nicotine Tob Res 2012;14:448-54. (A)

61 Abughosh S, Wu I-H, Rajan S, et al. Waterpipe smoking among students in one US university: predictors of an intention to quit. J Am Coll Health 2012;60: 528-35. (A)

62 Primack BA, Land SR, Fan J, et al. Associations of mental health problems with waterpipe tobacco and cigarette smoking among college students. Subst Use Misuse 2013:48:211-19. (A)

63 Primack BA, Shensa $A$, Kim KH, et al. Waterpipe smoking among US university students. Nicotine Tob Res 2013:15:29-35. (A,B,D)

64 Klassen BJ, Smith KZ, Grekin ER. Differential relationships between religiosity, cigarette smoking, and waterpipe use: implications for college student health. J Am Coll Health 2013;61:381-5. (A,B)

65 Blank MD, Brown KW, Goodman RJ, et al. an Observational study of group waterpipe use in a natural environment. Nicotine Tob Res 2014;16:93-9. (B)

66 Fielder RL, Carey KB, Carey MP. Predictors of initiation of hookah tobacco smoking: a one-year prospective study of first-year college women. Psychol Addict Behav 2012;26:963. (A)

67 Jamil H, Geeso SG, Arnetz BB, et al. Risk factors for hookah smoking among Arabs and Chaldeans. J Immigr Minor Health 2014;16:501-7. (A,B)

68 Kelishadi R, Mokhtari MR, Tavasoli AA, et al. Determinants of tobacco use among youths in Isfahan, Iran. Int J Public Health 2007;52:173-9. (A)

69 Erbaydar NP, Bilir N, Yildiz AN. Knowledge, behaviors and health hazard perception among Turkish narghile (waterpipe)-smokers related to narghile smoking. Pak J Med Sci 2010;26:195-200. (A)

70 Lipkus IM, Eissenberg T, Schwartz-Bloom RD, et al. Affecting perceptions of harm and addiction among college waterpipe tobacco smokers. Nicotine Tob Res 2011;13:599-610. (A)

71 Sabahy AR, Divsalar K, Bahreinifar $S$, et al. Waterpipe tobacco use among Iranian university students: correlates and perceived reasons for use. Int I Tuberc Lung Dis 2011;15:844-7. (A) 
72 Griffiths MA, Harmon TR, Gilly MC. Hubble bubble trouble: the need for education about and regulation of hookah smoking. J Public Policy Mark 2011;30:119-32. $(B, E)$

73 Ghafouri N, Hirsch J, Heydari G, et al. Waterpipe smoking among health sciences university students in Iran: perceptions, practices and patterns of use. BMC Res Notes 2011:4:496. (A)

74 Jawaid A, Zafar A, Rehman T, et al. Knowledge, attitudes, and practice of university students regarding waterpipe smoking in Pakistan. Int J Tuberc Lung Dis 2008;12:1077-84. (A)

75 Smith-Simone S, Maziak W, Ward KD, et al. Waterpipe tobacco smoking: knowledge, attitudes, beliefs, and behavior in two US samples. Nicotine Tob Res 2008:10:393-8. (A)

76 Giuliani KKW, Mire 0, Ehrlich LC, et al. Characteristics and prevalence of tobacco use among Somali youth in Minnesota. Am J Prev Med 2010;39(6 Suppl 1): S48-55. (A)

77 Martinasek MP, McDermott RJ, Bryant CA. Antecedents of university students hookah smoking intention. Am J Health Behav 2013;37:599-609. (A)

78 Afifi R, Khalil J, Fouad $F$, et al. Social norms and attitudes linked to waterpipe use in the Eastern Mediterranean Region. Soc Sci Med 2013;98:125-34. (A,B,C,D,E)

79 Combrink A, Irwin N, Laudin G, et al. High prevalence of hookah smoking among secondary school students in a disadvantaged community in Johannesburg. S Afr Med J 2010;100:297-9. (A)

80 Barnett TE, Curbow BA, Weitz JR, et al. Water pipe tobacco smoking among middle and high school students. Am J Public Health 2009;99:2014-19. (A)

81 Barnett TE, Shensa A, Kim KH, et al. The predictive utility of attitudes toward hookah tobacco smoking. Am J Health Behav 2013;37:433-9. (A)

82 Braun R. Hookah use among college students from a midwest university. J Community Health 2012;37:294-8. (A,B)

83 Hammal F, Mock J, Ward KD, et al. A pleasure among friends: how narghile (waterpipe) smoking differs from cigarette smoking in Syria. Tob Control 2008;7: e3. $(A, B)$

84 Giuliani KKW, Mire OA, Jama S, et al. Tobacco use and cessation among Somalis in Minnesota. Am J Prev Med 2008;5(6 Suppl):S457-62. (A)

85 Ahmed $B$, Jacob $P$, Allen $F$, et al. Attitudes and practices of hookah smokers in the San Francisco Bay Area. J Psychoactive Drugs 2011;43:146-52. (A,B)

86 Daniels KE, Roman NV. A descriptive study of the perceptions and behaviors of waterpipe use by university students in the Western Cape, South Africa. Tob Induc Dis 2013;11:4. (A)

87 Makhoul J, Nakkash R. Understanding youth: using qualitative methods to verify quantitative community indicators. Health Promot Pract 2009;10:128-35. (A,B)

88 Khalil J, Afifi R, Fouad FM, et al. Women and waterpipe tobacco smoking in the eastern Mediterranean Region: allure or offensiveness. Women Health 2013:53:100-16. (B)

89 Dillon KA, Chase RA. Secondhand smoke exposure, awareness, and prevention among African-born women. Am J Prev Med 2010;39(6 Suppl 1):S37-43. (B,E)

90 Wray RJ, Jupka K, Berman S, et al. Young adults' perceptions about established and emerging tobacco products: results from eight focus groups. Nicotine Tob Res 2012;14:184-90. (A,B,C,D,E)

91 Noonan D. A descriptive study of waterpipe smoking among college students J Am Acad Nurse Pract 2013;25:11-15. (A)

92 Roskin J, Aveyard P. Canadian and English students' beliefs about waterpipe smoking: a qualitative study. BMC Public Health 2009;9:10. (A,B)

93 Jamil $H$, Templin T, Fakhouri $M$, et al. Comparison of personal characteristics, tobacco use, and health states in Chaldean, Arab American, and non-Middle Eastern White adults. J Immigr Minor Health 2009;11:310-17. (A)

94 Labib N, Radwan G, Mikhail N, et al. Comparison of cigarette and water pipe smoking among female university students in Egypt. Nicotine Tob Res 2007;9:591-6. (A)

95 Primack BA, Sidani J, Agarwal AA, et al. Prevalence of and associations with waterpipe tobacco smoking among U.S. university students. Ann Behav Med 2008;36:81-6. (A,B)

96 Sidani JE, Shensa A, Barnett TE, et al. Knowledge, attitudes, and normative beliefs as predictors of hookah smoking initiation: A longitudinal study of university students. Nicotine Tob Res 2014;16:647-54. (A,B)

97 Eissenberg T, Ward KD, Smith-Simone $S$, et al. Waterpipe tobacco smoking on a U.S. college campus: Prevalence and correlates. J Adolesc Health 2008;42: 526-9. (A,B)

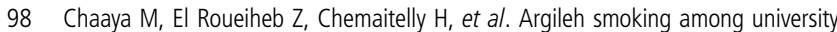
students: a new tobacco epidemic. Nicotine Tob Res 2004;6:457-63. (A)

99 Karimy M, Niknami S, Heidarnia AR, et al. Refusal self efficacy, self esteem, smoking refusal skills and water pipe (hookah) smoking among Iranian male adolescents. Asian Pac J Cancer Prev 2013;14:7283-8. (A)

100 Noonan D, Kulbok PA. Beliefs and norms associated with smoking tobacco using a waterpipe among college students. J Addict Nurs 2012;23:123-8. (A,B)

101 Abughosh S, Wu IH, Peters RJ, et al. Ethnicity and waterpipe smoking among US students. Int J Tuberc Lung Dis 2012;16:1551-7. (A,B)

102 Griffiths MA, Ford EW. Hookah smoking: behaviors and beliefs among young consumers in the United States. Soc Work Public Health 2013;29:17-26. (A)
103 Taha AZ, Sabra AA, Al-Mustafa ZZ, et al. Water pipe (shisha) smoking among male students of medical colleges in the eastern region of Saudi Arabia. Ann Saudi Med 2010;30:222. (A)

104 Al Nohair SF. Prevalence of Smoking and its related behaviors and beliefs among secondary school students in Riyadh, Saudi Arabia. Int J Health Sci 2011;5:51. (A)

105 Holtzman AL, Babinski D, Merlo LJ. Knowledge and attitudes toward hookah usage among university students. J Am Coll Health 2013;61:362-70. (A)

106 Chaaya M, Jabbour S, El-Roueiheb Z, et al. Knowledge, attitudes, and practices of argileh (water pipe or hubble-bubble) and cigarette smoking among pregnant women in Lebanon. Addict Behav 2004;29:1821-31. (A,B,D)

107 Dar-Odeh NS, Bakri FG, Al-Omiri MK, et al. Narghile (water pipe) smoking among university students in Jordan: prevalence, pattern and beliefs. Harm Reduct 2010;7:10. (A)

108 Zoughaib SS, Adib SM, Jabbour J, et al. Prevalence and determinants of water pipe or narghile use among students in Beirut's southern suburbs. J Med Liban 2004;52:142-8. (A)

109 Amin TT, Amr MAM, Zaza BO, et al. Predictors of waterpipe smoking among secondary school adolescents in Al Hassa, Saudi Arabia. Int J Behav Med 2012;19:324-35. (A)

110 Abughosh S. Predictors of persistent waterpipe smoking among university students in the United States. Epidemiology 2011;1:102.

111 Smith JR, Novotny TE, Edland SD, et al. Determinants of hookah use among high school students. Nicotine Tob Res 2011;13:565-72. (B)

112 Sutfina EL, McCoy TP, Reboussin BA, et al. Prevalence and correlates of waterpipe tobacco smoking by college students in North Carolina. Drug Alcohol Depend 2011;115:131-6. (A,B,C,E)

113 Noonan D, Patrick ME. Factors associated with perceptions of hookah addictiveness and harmfulness among young adults. Subst Abus 2013;34:83-5. (A)

114 Jamil $H$, Janisse J, Elsouhag $D$, et al. Do household smoking behaviors constitute a risk factor for hookah use?. Nicotine Tob Res 2011;13:384-8. (B)

115 Heinz AJ, Giedgowd GE, Crane NA, et al. A comprehensive examination of hookah smoking in college students: use patterns and contexts, social norms and attitudes, harm perception, psychological correlates and co-occurring substance use. Addict Behav 2013;38:2751-60. (A,B)

116 Kakodkar PV, Bansal SS. Hookah smoking: characteristics, behavior and perceptions of youth smokers in Pune, India. Asian Pac J Cancer Prev 2013;14:4319-23. (A)

117 Al-Naggar RA, Saghir FS. Water pipe (shisha) smoking and associated factors among Malaysian university students. Asian Pac J Cancer Prev 2011;12:3041-7. (A)

118 Anand NP, Vishal K, Anand NU, et al. Hookah use among high school children in an Indian city. J Indian Soc Pedod Prev Dent 2013;31:180. (A)

119 Smith SY, Curbow B, Stillman FA. Harm perception of nicotine products in college freshmen. Nicotine Tob Res 2007;9:977-82. (A)

120 Allam MF, Abd Elaziz KM. Role of members of university students' unions in tobacco prevention. J Prev Med Hyg 2007;48:136-40. (B)

121 Poyrazoglu S, Sarli S, Gencer Z, et al. Waterpipe (narghile) smoking among medical and non-medical university students in Turkey. Ups J Med Sci 2010;115:210-16. (A)

122 Azab M, Khabour OF, Alkaraki AK, et al. Water pipe tobacco smoking among university students in Jordan. Nicotine Tob Res 2010;12:606-12. (A)

123 Almerie MQ, Matar HE, Salam M, et al. Cigarettes and waterpipe smoking among medical students in Syria: a cross-sectional study. Int J Tuberc Lung Di 2008;12:1085-91. (A,B)

124 Afifi RA, Yeretzian JS, Rouhana A, et al. Neighbourhood influences on narghile smoking among youth in Beirut. Eur J Public Health 2010;20:456-62. (A,B)

125 Jawad M. Public health implications of shisha smoking in London. Department of Primary Care and Public Health, Imperial College London, 2013.

126 Ward KD, Eissenberg T, Gray JN, et al. Characteristics of US waterpipe users: a preliminary report. Nicotine Tob Res 2007;9:1339-46. (A,B)

127 Smith-Simone SY, Curbow BA, Stillman FA. Differing psychosocial risk profiles of college freshmen waterpipe, cigar, and cigarette smokers. Addict Behav 2008;33:1619-24. (A,B)

128 Sharma E, Beck KH, Clark PI. Social context of smoking hookah among college students: scale development and validation. J Am Coll Health 2013;61:204-11. (B)

129 Bejjani N, El Bcheraoui C, Adib SM. The social context of tobacco products use among adolescents in Lebanon (MedSPAD-Lebanon). J Epidemiol Glob Health 2012:2:15-22. (B)

130 Mzayek F, Khader Y, Eissenberg T, et al. Design, baseline results of Irbid longitudinal, school-based smoking study. Am J Health Behav 2011;35:746-55. (A,B)

131 Mohammed HR, Zhang Y, Newman IM, et al. Waterpipe smoking in Kuwait. East Mediterr Health J 2010;16:1115-20. (B)

132 Tamim H, Al-Sahab B, Akkary G, et al. Cigarette and nargileh smoking practices among school students in Beirut, Lebanon. Am J Health Behav 2007;31:56-63. (A)

133 Abughosh S, Yang M, Wu I-H, et al. Waterpipe smoking among Jordanian adults: predictors and correlates. J Behav Health 2012;1:7-15. (A)

134 Jawad $\mathrm{M}$, Wilson A, Lee JT, et al. Prevalence and predictors of water pipe and cigarette smoking among secondary school students in London. Nicotine Tob Res 2013;15:2069-75. (A)

135 Al-Lawati JA, Muula AS, Hilmi SA, et al. Prevalence and determinants of waterpipe tobacco use among adolescents in Oman. Sultan Qaboos Univ Med J 2008:8:37-43. (A,B) 
136 Salameh P, Salame J, Waked M, et al. Waterpipe dependence in university students and effect of normative beliefs: a cross-sectional study. BMJ Open 2014;4:e004378. (A)

137 Jamil H, Elsouhag D, Hiller S, et al. Sociodemographic risk indicators of hookah smoking among White Americans: a pilot study. Nicotine Tob Res 2010;12:525-9. $(A, B)$

138 Malik S, Shafagoj Y, Abdeen D, et al. Youth Attitudes towards Water Pipe Smoking in Amman-Jordan. 2013 (A)

139 Al-Naggar RA, Bobryshev YV. Shisha smoking and associated factors among medical students in Malaysia. Asian Pac J Cancer Prev 2012;13:5627-32. (A)

140 Jawad M, Abass J, Hariri A, et al. Waterpipe smoking: prevalence and attitudes among medical students in London. Int J Tuberc Lung Dis 2013;17:137-40. (A)

141 Wali SO. Smoking habits among medical students in western Saudi Arabia. Saudi Med J 2011;32:843-8. (A)

142 Martins SR, Paceli RB, Bussacos MA, et al. Experimentation with and knowledge regarding water-pipe tobacco smoking among medical students at a major university in Brazil. J Bras Pneumol 2014;40:102-10. (A,B)

143 Van der Merwe N, Banoobhai T, Gqweta A, et al. Hookah pipe smoking among health sciences students. S Afr Med J 2013;103:847-9. (A)

144 Jradi $\mathrm{H}$, Wewers ME, Pirie PP, et al. Cigarette and waterpipe smoking associated knowledge and behaviour among medical students in Lebanon. East Mediterr Health I 2013;19:861-8. (C)

145 Khan AA, Dey S, Taha AH, et al. Attitudes of Cairo University medical students toward smoking: the need for tobacco control programs in medical education. J Egypt Public Health Assoc 2012;87:1-7. (A)

146 Vanderhoek AJ, Hammal F, Chappell A, et al. Future physicians and tobacco: an online survey of the habits, beliefs and knowledge base of medical students at a Canadian University. Tob Induc Dis 2013;11:9. (A)

147 Jawad M, Khaki H, Hamilton F. Shisha guidance for GPs: eliciting the hidden history. Br J Gen Pract 2012;62:66-7.

148 Nakkash RT, Khalil J, Afifi RA. The rise in narghile (shisha, hookah) waterpipe tobacco smoking: a qualitative study of perceptions of smokers and non smokers. BMC Public Health 2011;11:315. (A,B,C)

149 Jackson D, Aveyard P. Waterpipe smoking in students: prevalence, risk factors, symptoms of addiction, and smoke intake: evidence from one British university. BMC Public Health 2008;8:5. (A)

150 Maziak W, Rastam S, Eissenberg T, et al. Gender and smoking status-based analysis of views regarding waterpipe and cigarette smoking in Aleppo, Syria. Prev Med 2004;38:479-84. (A,B)

151 Primack BA, Rice KR, Shensa A, et al. U.S. hookah tobacco smoking establishments advertised on the internet. Am J Prev Med 2012;42:150-6. (D)

152 Carroll MV, Shensa A, Primack BA. A comparison of cigarette- and hookah-related videos on YouTube. Tob Control 2013;22:319-23. (D)

153 Sterling KL, Fryer CS, Majeed B, et al. Promotion of waterpipe tobacco use, its variants and accessories in young adult newspapers: a content analysis of message portrayal. Health Educ Res Published Online First: 23 June 2014. doi:10.1093/her/ cyu035

154 Khalil J. Lebanon: diet hookah. Tob Control 2010;19:351.

155 Khalil J, Heath RL, Nakkash RT, et al. The tobacco health nexus? Health messages in narghile advertisements. Tob Control 2009;18:420-1. (C)

156 Primack BA, Hopkins M, Hallett C, et al. US health policy related to hookah tobacco smoking. Am J Public Health 2012;102:e47-51. (E)

157 Nakkash R, Khalil J. Health warning labelling practices on narghile (shisha, hookah) waterpipe tobacco products and related accessories. Tob Control 2010;19:235-9. (E)
158 Morris DS, Fiala SC, Pawlak R. Opportunities for policy interventions to reduce youth hookah smoking in the United States. Prev Chronic Dis 2012;9:E165.

159 Noonan D. Exemptions for hookah bars in clean indoor air legislation: a public health concern. Public Health Nurs 2010;27:49-53.

160 Bahelah R. Waterpipe tobacco labeling and packaging and World Health Organization Framework Convention on Tobacco Control (WHO FCTC): a call for action. Addiction 2014;109:333.

161 Jawad M, Millett C. Impact of EU flavoured tobacco ban on waterpipe smoking. BMJ 2014;348:g2698.

162 Mohammed HT. The efficacy of viewing health warnings on shisha smoking among shisha smokers [dissertation on the Internet]. Ontario, Canada: Waterloo, 2013 [cited 24 Sepember 2014]. https://uwspace.uwaterloo.ca/bitstream/handle/ 10012/7419/Mohammed_HebaTallah.pdf?sequence $=1$

163 Grekin ER, Ayna D. Argileh use among college students in the United States: an emerging trend. J Stud Alcohol Drugs 2008;69:472. (A)

164 Highet G, Ritchie D, Platt S, et al. The re-shaping of the life-world: male British Bangladeshi smokers and the English smoke-free legislation. Ethn Health 2011;16:519-33.

165 Zyoud SH, Al-Jabi SW, Sweileh WM. Bibliometric analysis of scientific publications on waterpipe (narghile, shisha, hookah) tobacco smoking during the period 20032012. Tob Induc Dis 2014;12:7.

166 Pepper JK, Eissenberg T. Waterpipes and electronic cigarettes: increasing prevalence and expanding science. Chem Res Toxicol 2014;27:1336-43.

167 WHO M-POWER. http://www.who.int/tobacco/mpower/en/ (accessed 25 Sep 2014).

168 Centers for Disease Control and Prevention. Best practices for comprehensive tobacco control programs. Atlanta: CDC, Office on Smoking and Health, 2014.

169 Maziak W, Ward KD, Afifi Soweid RA, et al. Tobacco smoking using a waterpipe: a re-emerging strain in a global epidemic. Tob Control 2004;13:327-33.

170 Myslin M, Zhu SH, Chapman W, et al. Using twitter to examine smoking behavior and perceptions of emerging tobacco products. J Med Internet Res 2013;15:e174. $(A, B, C)$

171 Brockman LN, Pumper MA, Christakis DA, et al. Hookah's new popularity among US college students: a pilot study of the characteristics of hookah smokers and their Facebook displays. BMJ Open 2012;2:pii: e001709.

172 Legacy Foundation. http://www.youtube.com/watch?v=pTgxMSjbF7Q

173 Abouaziza E, Eissenberg T. Waterpipe tobacco smoking: what is the evidence that it supports nicotine/tobacco dependence? Tob Control 2015;24:i44-53.

174 Kumar R, Davies S, Weitzman M, et al. A review of air quality, biological indicators and health effects of secondhand waterpipe smoke exposure. Tob Control 2015;24: i54-59.

175 Jawad M, Jawad S, Mehdi A, et al. A qualitative analysis among regular waterpipe tobacco smokers in London universities. Int I Tuberc Lung Dis 2013;17:1364-9. (A)

176 Jawad M, McEwen A, McNeill A, et al. The importance of addressing waterpipe tobacco smoking: research and policy responses. Addiction 2013;108:1887-8.

177 Weinstein ND. Misleading tests of health behavior theories. Ann Behav Med 2007;33:1-10.

178 Ottersen OP, Dasgupta J, Blouin C, et al. The Lancet-University of Oslo Commission on Global Governance for Health: the political origins of health inequity: prospects for change. Lancet 2014;383:630-67.

179 Collin J. Global health policy and development: towards policy coherence in global governance. Tob Control 2012;21:274-80.

180 Kickbusch I. Mapping the future of public health: action on global health. Can J Public Health 2006;97:6-8. 